\title{
The influence of placements on adult nursing graduates' choice of first post
}

\author{
Mark Wareing, Renate Taylor, Aileen Wilson and Adrienne Sharples
}

\begin{abstract}
AQ1: need an abstract in the usual research article format: background, then aims/method/results/conclusions for the pilot study
\end{abstract}

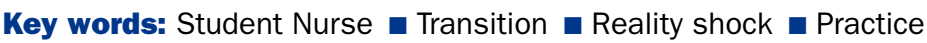
Placement $\boldsymbol{\nabla}$ Recruitment and Retention

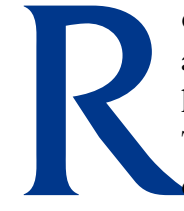

ecruiting a stable workforce with appropriate skills and knowledge is vital to ensuring the provision of high quality care within a safe clinical environment. There is a clear link between staffing ratios and quality of care (Smith, 2007; Aiken et al, 2014; Addicott et al, 2015; Royal College of Nursing (RCN), 2016). The challenges of recruitment and retention in nursing are however, well documented. It is estimated that there are 20000 vacant nursing posts in the UK (Health Education England, 2015; Smith and Baltruks, 2015) [AQ2: Totting up the estimates for vacancies in 2014 quoted in the 2015/16 plan gives 18000. The 2016/17 plan says 26700 vacancies in 2015 (p27)]. The most popular career choices for newly qualified nurses (NQNs) are acute and highly technical areas such as

Mark Wareing, Director of Practice Learning, University of Bedfordshire

Renate Taylor, Senior Lecturer Mental Health Nursing, University of Bedfordshire

Aileen Wilson, Senior Lecturer Adult Nursing, University of Bedfordshire, aileen.wilson@beds.ac.uk

Adrienne Sharples, Senior Lecturer, Pre-professional healthcare education, University of Bedfordshire

Accepted for publication: February 2017 emergency and critical care, while primary care and care of the elderly are less popular (Hapell, 1999; Palese et al, 2007; Bloomfield et al, 2015). The vacancy rate in some of these less popular specialisms is as high as $20 \%$ (Foot et al, 2014). This nursing shortfall is compounded by high attrition rates, with an estimated 25000 nurses expected to leave the profession in 2016 (Smith and Baltruks, 2015). Health Education England (2014) has suggested that significant contributors to the problem are job dissatisfaction, stress and burnout. Poor retention of staff jeopardises patient outcomes, threatens safety and increases the stress and anxiety level of nurses (Smith and Baltruks, 2015). This leads to further attrition and perpetuates the problem.

NQNs are a particularly vulnerable group, with high attrition rates during their first 2 years in post (Dulcos-Miller, 2011). This has been attributed to high levels of stress and burnout, or 'reality shock', among NQNs (Rudman and Gustavsson, 2011; Parker et al, 2014 [AQ3: missing ref]). This phenomenon was first identified by Kramer (1974), who recognised that the gap between the graduate nurses' expectations and the realities of professional practice results in role conflict and stress. Phillips et al (2014) found that graduates entering highly specialised areas felt that their skill set was too basic for the level of patient acuity and that this increased stress. Matching the graduate's skills with those required in their first destination post is pivotal in facilitating a smooth transition into the profession (Burke et al, 2014). Developing strategies to support student nurses in matching their skill set to their first destination post will help to reduce reality shock and improve retention of NQNs.

It has also been argued that the reduction in practice placement time associated with the move from the apprenticeship model into university based programmes has resulted in inadequate preparation of students for professional practice thereby compounding reality shock (Higgins et al, 2010: Smith and Baltruks, 2015). This suggests that there is a need to focus on improving the practice experience in order to prepare students for the realities of the profession (Allan and Smith, 2009).

This pilot study examined the influence of placements on the career choices of adult field student nurses in aneast of England university. The findings will be used in the development of a larger mixed-methods study examining this issue across adult, mental health and child nursing fields. The new knowledge generated will contribute towards promotion of less popular specialisms and development of a decision-making tool to help final year nursing students select their first staff nurse post. This will facilitate a smoother transition into the role of 
newly qualified nurse and contribute to improved recruitment and retention, ultimately leading to improved quality of care.

\section{Literature review}

Much of the literature relating to the transition from student to newly qualified nurse focuses on graduates in their first staff nurse post. Relatively few studies have focused on student nurses.

In their longitudinal study Rognstad and Aasland (2007) compared 221 Norwegian student nurses' career predictions on commencement of the preregistration programme with their choice at graduation. Students' values and motivation for choice were also assessed. The study found no significant change in career preferences with midwifery, public health and 'high-tech' areas remaining popular throughout. Motivators did however change from altruistic values such as helping others, to the more extrinsic values of salary and job security. In contrast, a larger study by Kloster et al (2007) found that career preferences changed significantly during the pre-registration programme. In this longitudinal study of 620 student nurses from 5 Norwegian universities, students' preferences changed from midwifery and children's nursing at commencement of the course to medical and surgical nursing in the final year. Elderly care remained consistently unpopular throughout the programme.

These findings are supported by more recent Australian and UK studies. Stevens (2011) used a repeated-measures survey to examine Australian student nurses' career preferences and found high-tech acute areas to be the most popular and elderly care the least popular. Interestingly initially $8 \%$ of participants expressed a preference for elderly care but this had declined to less than $1 \%$ by the end of the programme. McCann et al (2010) also used a repeated-measures design to examine whether the career preferences of 96 Australian nurses changed during the 3 -year course. The most popular choice was again acute adult care and this remained consistent across 3 years. However, there were changes in the second- and third-ranked preferences, with midwifery and children's nursing decreasing in popularity and mental health nursing becoming more popular during the programme. Elderly care remained unpopular throughout the course. Participants in this study were asked to select from a restricted list of options and this may have influenced the results. The findings are consistent with a further Australian study, in which Birks et al (2010) explored the career choices and aspirations of 163 Australian student nurses. Students ranked their preferences for the specialism and location of their first destination post. Midwifery was ranked by $27 \%$ of participants as their first preference. Emergency care and children's nursing were the second and third most popular options. This study also found a strong correlation between where the participant originated and where they wanted to work, with students originating from rural areas more likely to want to work there. The authors argued the importance of 'growing your own' as I a means to resolve recruitment problems, but acknowledged the potential bias created by the high proportion of students originating from rural areas. However, differences in both the preregistration nursing programmes and healthcare systems in Australia mean that these studies may not be directly applicable to the UK.
In their exploratory study Harris et al (2013) found a link between study location and career choice. Routinely collected demographic data from 8 UK universities were analysed and 804 student nurses were surveyed at graduation and again 3 months later. Findings indicated that $88 \%$ of graduates were offered a post in the city in which they studied and $67 \%$ were recruited to an area in which they had completed a course placement. The study was confined to one cohort of students in one city therefore may not be representative of other cities and academic years; however, it does highlight the potential influence of practice placements on the decision-making process. Bloomfield et al (2015) argued that there is no association between students' clinical placement experience and their career choice. This was based on the fact that $98 \%$ of students in their study [AQ4: what was the context for this? UK students? One university or several?] had been exposed to primary care placements, but only $23 \%$ identified it as a career option. This study did not address the reasons for choice of career and it is possible that newly qualified nurses may have wished to consolidate their skills prior to taking up a post in the community.

All of these studies presented similar findings. All but one suggested that career preferences change over time and all of them indicated a preference for acute areas with elderly care being consistently unpopular. Only one study considered the role of practice placements in career choice and this did not examine the factors influencing the decision. The majority of the literature relevant to this area originates from Australia, where the balance between the theoretical and practice aspects of the preregistration programme differ from those in the UK. There is a paucity of UK literature focusing on student nurses' career decisions. There is a clear need for further study in this area, therefore this pilot study asked how adult nursing students make decisions about their first staff nurse appointment.

\section{Aim and objectives \\ Aim}

This pilot study aimed to explore the influence of practice placements on final-year student nurses' career decisions.

\section{Objectives}

- Critically examine the influence of student practice placements on the graduate nurses choice of specialism

- Examine changes in student's career preferences across the 3-year programme

- Develop recommendations for UK nursing educational programme commissioners and higher education institute programme providers.

- Use the findings to create a decision tree to assist students in selecting their first destination post.

\section{Sample and methods}

This mixed-methods study uses a validating quantitative data variant of the concurrent triangulation design. In this type of study quantitative and qualitative data are of equal weight and are collected in a single phase often using a single instrument such as a survey (Creswell, 2003). Final-year students on the verge of registration as qualified nurses were recruited to the pilot 


\section{Box 1. Summary of questions}

- When you started the course, did you have in mind a particular clinical area of nursing that you thought you would like to work in as a staff nurse? Please identify what clinical area of nursing that you had in mind.

- Since starting your course have you ever thought that you should have chosen an alternative field of nursing?

If yes how often did you think this

- At the end of your first year did you have in mind a clinical area of nursing that you thought you would like to work in as a newly qualified staff nurse?

- If 'Yes', please identify what clinical area of nursing that you had in mind.

- During your first year, what if any impact did your placements have on the area of clinical nursing that you had in mind to work in as a newly qualified nurse?

- During your second year, what if any impact did your placements have on the area of clinical nursing that you had in mind to work in as a newly qualified nurse?

- Which placement, if any, has had the most influence on the area of clinical nursing that you now have in mind to work in as a newly qualified staff nurse?

- Please explain what it was about this placement that has influenced your decision to want to work there as a newly qualified staff nurse?

Have you, or do you intend to, apply for a staff nurse post in this placement?

- Overall, how important have your placements been in helping you to decide where you want to work as a newly qualified staff nurse?

- Are there any other comments that you would like to share regarding the influence that your placements have had in relation to your first staff nurse post?

study via the university's student online learning management system. The target population was a single cohort of 61 finalyear adult field student nurses divided across two campuses in an east of England university. All participants were female in the age range 18-51 years. A total of 35 completed questionnaires were returned (response rate 57\%).

Qualitative and quantitative data were collected in a single phase using a questionnaire (Box 1) distributed to participants on the final day of the course. This approach allowed participants time to complete the questionnaire on site and avoid the problems associated with low response rates for postal questionnaires and online surveys (Parker and Dewey, 2000; Shih and Fan, 2008 [AQ6: see ref list]).

\section{Ethical considerations}

The university's Institute of Healthcare Research granted ethical approval for the study. Participation was voluntary and written consent was obtained from all participants who were free to withdraw from the study at any time.All data have been anonymised and pseudonyms have been used in this report.

\section{Data analysis}

The demographic characteristics of the sample were transposed onto a spreadsheet and responses converted into nominal and ordinal scales. Descriptive analysis was completed including frequency (expressed in percentages and absolute numbers). Raw data was collated and analysed using SPPS v22.

The data from the free-text questions was transcribed and then analysed independently by the three members of the research team using constant comparative analysis. Constant comparative analysis is defined as a qualitative analysis that generates successive abstract concepts and theories through the inductive process of comparing data with data, data with categories, categories with categories and categories with concepts (Gray, 2014: 680). In this study each member of the research team read the transcribed free-text comments through a process of focused reading, to identify key words or phrases. The team then undertook analytical coding that revealed the properties of each code and therefore a theoretical explanation of the free-text data.

\section{Analysis \\ Quantitative data}

Demographic data indicated that the majority of the participants were in the 18-24 years and 25-31 years age categories (Table 1). As illustrated in Table 2, the majority of participants $66 \%(n=23)$ originated locally (within the county of study or an adjacent county). The participants responded with preferences for 24 clinical placements, these were aggregated into 7 categories to facilitate analysis (Table 3). No statistically significant relationship was found between the age of the participant and their preferred placement.

Eighteen participants (51\%) entered the course with preconceived preferences for clinical specialisms, however, only five of these $(14 \%)$ applied for first-destination posts in that specialism. Five participants (14\%) went on to apply for posts in clinical areas that they had identified as a preference at the end of year 1 and a further 16 (46\%) applied for posts in placement areas they identified as the most influential placement at the end of year 3 .

The overall importance of placements in career choice increased across the 3 years of the programme, as can be seen in Figure 1. It is clear from this that the placements in all three years are important, however the experiences in year 3 are pivotal, with $74 \%$ ranking these as 'significantly influential' in their decision making process.

Overall participants indicated that practice placement experience was a key influencing factor in the choice of first destination post, with $6 \%(\mathrm{n}=2)$ ranking placements as fairly important 29\% ( $\mathrm{n}=10)$ ranking them as quite important and $66 \%$ ranking them as significant in the decision-making process. In total $74 \%(n=26)$ participants intended to apply for posts in the placement they found to be most influential, clearly illustrating the overall importance of placement experience in their career choice.

\section{Qualitative data}

Analysis of the data obtained from the free text questions identified four key themes:

- The working environment

- Support and development

- Making a difference

- Influence of placements.

\section{The working environment}

The participants expressed a preference for fast-paced acute environments with a variety of patients. However, although the majority of participants highlighted a preference for a fast pace of work, this was not universally true, with some expressing a preference for the more relaxed pace in community nursing:

'More time to nurse, reflect, make decisions, 
less impact on health and ongoing ability to continue in nursing.'

Jane

Several participants made a connection between the pace of work and learning, for instance:

'I enjoy the fast-paced environment, gives you lots of opportunities to learn about different surgical procedures.'

Sarah

Overall there was a perceived association between fast-paced acute areas and more learning opportunities.

\section{Support and development}

The opportunity to learn and develop new skills and confidence was commonly recurring theme and several participants linked this with the level of support from the team and mentors:

'Good mentors and staff were happy to teach and helped me to build confidence and become more competent. They pushed me towards learning opportunities and allowed me to take on a leadership role.'

Mariam

In contrast to this some participants emphatically stated that they would not consider returning to areas where they perceived that there were low staffing levels and insufficient support.

'Lack of staffing, lack of support-convinced me not to [go] back.'

Siobhan

'Less supportive placement $=$ less likely to want to work in that environment.'

Rhiannon

\section{Making a difference}

In addition to the support and learning opportunities available in the clinical specialism the opportunity to make a difference to patients' lives was influential in the decision making process. One participant summed this up clearly in her statement:

'This was a very rewarding placement because it was nice to know I was helping patients improve physically and psychologically.'

Sarbjit

\section{Influence of placements}

Participants clearly indicated that experiencing a variety of placements helped them to decide which areas they wanted

to work in and which they did not:

'Good placements increased my areas of interest so made the decision harder, bad placements enabled me to rule specialities out.'

Patience

\section{Table 1. Age distribution}

18-24 years

$49 \%$

25-31 years

$31 \%$

32-37 years

$3 \%$

38-44 years

$11 \%$

45-51 years

$6 \%$

Table 2. Origins of participants

Local

$66 \%$

Distant

$31 \%$

Unknown

$3 \%$

Table 3. The most influential placement categories

Category of clinical placement

Percentage ranking as most influential

Acute medical/surgical

$49 \%(n=17)$

Primary care

$17 \%(n=6)$

Emergency care

$11 \%(n=4)$

Elderly

$9 \%(n=3)$

Theatre

$6 \%(n=2)$

Critical care

$6 \%(n=2)$

Rehabilitation

$3 \%(n=1)$

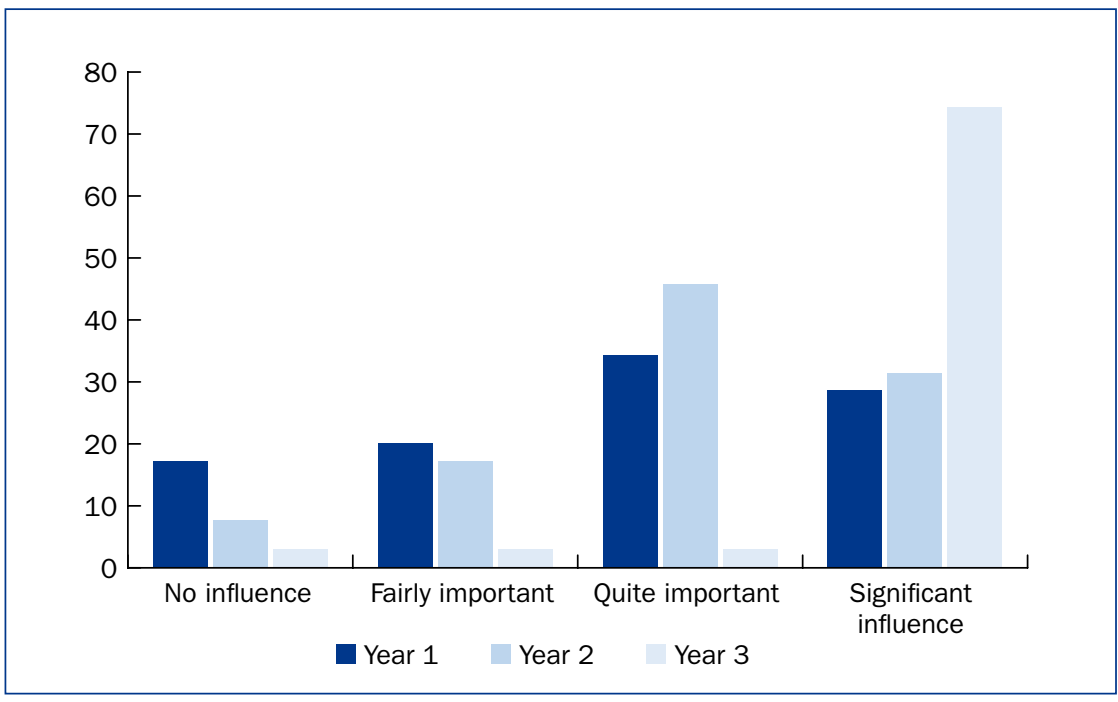

Figure 1. Influence of practice placements on career choice by year of programme (expressed in percentages).

Participants emphasised the importance of the final-year placements in helping them to make a decision:

'Last placement gives a bigger impact on how you would work within the staff [sic] and how you'd be included.'

Marianna [AQ7:Two very similar pseudonyms used - just to check they are 2 people rather than typo] 
Having experience in the area they selected for their first destination post gave participants confidence and helped them to see how they would fit into the team.

\section{Discussion}

In keeping with previous studies (Hapell, 1999; Palese et al,2007; Bloomfield et al, 2015), these findings mirrored participants' preferences for fast-paced acute areas with acute medicine and surgery being the most popular options. However, contrary to previous findings, elderly care was not the least popular option, this position was instead occupied by rehabilitation. The preference for fast-paced areas is concerning in the light of Kuman and Carney's (2014) findings, which suggested that reality shock was intensified by the increased pace of work experienced by NQNs. It is ironic that one of the main attractions of the chosen specialism is one of the key stressors. Phillips et al (2014) suggested that popular career choices may not be appropriate for the basic skill set of NQNs and Burke et al (2014) emphasised the need to match the graduate's skills with those required in their first post. This strongly suggests that a decision-making tool used in conjunction with coaching from academic staff may be of benefit.

Only five participants applied for first destination posts in the area they identified as their preferred career option at the start of the programme. This indicates that career preferences can be changed by education and exposure to a variety of different practice placements. This is further supported by the fact that a clear majority of participants ranked the overall impact of placements as 'significantly influential' with final-year placements being the most important. Participants identified that positive influencing factors were the variety of patients, support from the team and mentors, availability of learning opportunities and the opportunity to make a difference. Negative influencing factors were short staffing and lack of support. The fact that over $74 \%$ of participants intended to apply for the placement they felt was most influential clearly indicates that practice experience is pivotal in career choice and implies that provision of positive placement experiences may contribute to resolution of the recruitment crisis in nursing.

Ensuring a smooth transition from student to staff nurse is central to retention of staff (Rush et al, 2013). In their study Maxwell et al (2011) noted that the transition was less difficult for students who had trained in the Trust in which they took up their first staff nurse post. Familiarity with the ward routines and rituals may reduce stress and help to facilitate a smooth transition into the staff nurse role (Allan et al, 2015; Kuman and Carney, 2015).The fact that the majority of participants applied for first destination posts in areas in which they had been placed as a student is encouraging as this may help to reduce reality shock and improve retention of graduates. However, further research is need to determine if this is the case.

Findings indicated that students were attracted to areas where they felt supported by their mentors and the wider team. Participants were clear that they did not wish to return to work areas where support was poor. It is interesting to note that although students did mention their mentors, the emphasis was on the support from the team as a whole. Traditionally support for students in practice has focused on the role of the mentor; however, this study suggests that this may need to be extended to the wider team to ensure that all nurses contribute to the provision of good-quality practice experiences in order to attract new graduates and ensure sufficient numbers of qualified nurses to provide high-quality care in the future.

\section{Limitations}

This was a small pilot study limited to one cohort in one university in the East of England; as such the results may not be applicable to students in other academic years or locations. In addition all participants were female therefore the results may not apply to male students. The small sample size also limited the potential for statistical analysis.

\section{Conclusions and future work}

This study has highlighted the key role of practice placements in the career choices of student nurses. It has shown that students are likely to apply for posts in the placement area they found to be most supportive and it is possible that returning to a familiar area may reduce reality shock thereby reducing attrition and creating a more stable workforce. There is a clear benefit in investment in provision of high-quality clinical placement experiences that encourage students to return to that area as qualified nurses, this is of particular importance for the less popular specialisms such as elderly care. Failure to recruit and high attrition rates lead to low staffing levels, which then lead to poor standards of care and poor patient outcomes. Understaffing leads to poor teamwork and lack of support, resulting in negative practice experiences, which in turn discourages students from returning to that area as an NQN.

The main objective of this study was to pilot a survey instrument for use in a larger study; however, it has yielded some interesting data. While is impossible to generalise from such a small sample, the findings echoed those of previous studies. It is beyond the scope of this pilot study to make recommendations for wider practice but the results indicate that there is a need for universities, mentors and the wider teams within placement areas to work collaboratively to provide high-quality experiences which prepare the student for professional practice and reduce reality shock, thereby enhancing recruitment and retention. Finally a future longitudinal study, following graduates into the first two years of employment, is needed to ascertain whether gaining employment in a previous practice placement has any impact on reality shock. BJN

\section{Declaration of interests: none}

Addicott R, Maguire D, Honeyman M, Jabbal J (2015) Workforce Planning in the NHS. The King's Fund, London. http://tinyurl.com/hrletoj (accessed 8 February 2016)

Aiken LH, Sloane DM, Bruyneel L et al for RN4CAST consortium (2014) Nurse staffing and education and hospital mortality in nine European countries: a retrospective observational study. Lancet 383(9931): 1824-30. https://dx.doi.org/10.1016/S0140-6736(13)62631-8

Allan HT, Smith PA (2009) How student nurses' supernumerary status affects the way they think about nursing: a qualitative study. Nurs Times 105(43): $10-13$

Allan HT, Magnusson C, Horton K et al (2015) People, liminal spaces 
and experience: understanding recontextualisation of knowledge for newly qualified nurses. Nurse Educ Today 35(2):e78-83. https://dx.doi. org/10.1016/j.nedt.2014.10.018. Epub 2014

Birks M, Al-Motlaq M, Mills J (2010) Pre-registration nursing degree students in rural Victoria: Characteristics and career aspirations. Collegian 17(1): 23-9. https://dx.doi.org/10.1016/j.colegn.2009.07.001

Bloomfield JG, Gordon CJ, Williams AM, Aggar C (2015) Nursing students intention to enter primary health care as a career option: findings from a national survey. Collegian 22(2): 161-7. https://dx.doi.org/10.1016/j. colegn.2015.02.001

Burke L, Sayer J, Morris-Thompson T, Marks-Maran D (2014) Recruiting competent newly qualified nurses in the London region: An exploratory study. Nurse Educ Today 34(10):1283-9. https://dx.doi.org/10.1016/j. nedt.2014.02.002

Creswell JW (2003) Research Design: Qualitative Quantitative and Mixed Methods Approaches. 2nd edn. Sage Publications, Thousand Oaks [AQ8:There's since been 3 rd and 4th edns - stick with 2nd or reference the later ones?]

Dulcos-Miller PA (2011) Successful graduate nurse transition: meeting the challenge. Nurse Leader 9(4): 32-35, 49. https://dx.doi.org/10.1016/j. mnl.2011.05.006

Foot C, Sonola L, Bennett L, Fitzsimons B, Raleigh V, Gregory S (2014) Managing Quality in Community Health Care Services. The King's Fund, London. http://tinyurl.com/lke5u48 (accessed 8 February 2017)

Gray DE (2014) Doing Research in the Real World. 3rd edn. Sage Publications, London

Happell B (1999) When I grow up I want to be a...? Where undergraduate students want to work after graduation. J Adv Nurs 29(2): 499-505

Harris R, Ooms A, Grant R et al (2013) Equality of employment opportunities for nurses at the point of qualification: an exploratory study. Int J Nurs Stud 50(3): 303-13. https://dx.doi.org/10.1016/j ijnurstu.2012.10.008. Epub 2012

Health Education England (2014) Growing Nursing Numbers: Literature review on nurses leaving the NHS. http://tinyurl.com/zjqbqlu (accessed 8 February 2017)

Health Education England (2015) Workforce Plan for England: Proposed Education and Training Commissions 2015/16. (Investing in people for health and healthcare) Health Education England, Leeds. http://tinyurl.com/jbgt3oh (accessed 8 February 2017) [related to AQ2: Did you want to refer to the 2016/17 plan? https://www.hee.nhs.uk/sites/default/files/documents/ Workforce\%20Plan\%20for\%20England\%202016-17.pdf

Higgins G, Spencer RL, Kane R (2010) A systematic review of the experiences and perceptions of the newly qualified nurse in the United Kingdom. Nurse Educ Today 30(6): 499-508. https://dx.doi.org/10.1016/j. nedt.2009.10.017

Kloster T, Høie M, Skår R (2007) Nursing students' career preferences: a Norwegian study. J Adv Nurs 59(2): 155-62. https://dx.doi.org/10.1111/ j.1365-2648.2007.04276.x

Kramer M (1974) Reality Shock: Why Nurses Leave Nursing. Mosby, St Louis

Kuman S, Carney M (2014) Role transition from student nurse to staff nurse: Facilitating the transition period. Nurse Educ Pract 14(6): 605-11. https:// dx.doi.org/10.1016/j.nepr.2014.06.002

Maxwell C, Brigham L, Logan J, and Smith A (2011) Challenges facing newly qualified community nurses: a qualitative study. Br J Community Nurs 16(9): 428-34. https://dx.doi.org/10.12968/bjen.2011.16.9.428

McCann TV, Clark E, Lu S (2010) Bachelor of nursing students career choices: a three-year longitudinal study. Nurse Educ Today 30(1): 31-6. https:// dx.doi.org/10.1016/j.nedt.2009.05.014

\section{KEY POINTS}

- AQ10: please provide 4 or 5 sentences to sum up main mesages for readers

Palese A, Tosatto D, Borghi G, Maura M (2007) Factors influencing the choice of the first ward: comparison between newly qualified nurses and managers. J Nurs Manag 15(1): 59-63. https://dx.doi.org/10.1111/j.13652934.2006.00654.x

Parker CJ, Dewey ME for the TOTAL Study Group (2000) Assessing research outcomes by postal questionnaire with telephone follow up. Int J Epidemiol 29(6): 1065-9. https://doi.org/10.1093/ije/29.6.1065

Phillips C, Kenny A, Esterman A, Smith C (2014) A secondary data analysis examining the needs of graduate nurses in their transition to a new role. Nurse Educ Pract 14(2): 106-11. https://dx.doi.org/10.1016/j. nepr.2013.07.007

Rognstad MK, Aasland O (2007) Change in career aspirations and job values from study time to working life. J Nurs Manag 15(4): 424-32. https:// dx.doi.org/10.1111/j.1365-2834.2007.00655.x

Royal College of Nursing (2016) Royal College of Nursing response to Health Education England's consultation: Building Capacity to Care and Capability to Treat-A New Team Member for Health and Social Care, March 2016. http:// tinyurl.com/hr4vphu (accessed 8 February 2017)

Rudman A, Gustavsson JP (2011) Early-career burnout among new graduate nurses: a prospective observational study of intra-individual change trajectories. Int J Nurs Stud 48(3): 292-306. https://dx.doi.org/10.1016/j. ijnurstu.2010.07.012

Rush KL, Adamack M, Gordon J, Lilly M, Janke R (2013) Best practices of formal new graduate nurse transition programs: an integrative review. Int J Nurs Stud 50(3):345-56. https://dx.doi.org/10.1016/j. ijnurstu.2012.06.009. Epub 2012

Shih T, Fan X (2008 [re AQ6: Only date of publication I can find online says 2012]) Comparing response rates from web and mail surveys: a metaanalysis. In: Hughes J, ed, SAGE Internet Research Methods. Volume Two: Taking Research Online: Internet Surveys And Sampling. SAGE Publications, London

Smith S (2007) What Contribution Can Acuity Dependency Scoring Make To Nursing Work Force Planning? Manchester Business School, Manchester. [AQ9: cannot see this online, only cited in article by Fanneran et al 2015 Was it a Masters thesis? $\mathrm{PhD}$ thesis?]

Smith C, Baltruks D (2015) The Nursing Journey: Recruitment and Retention. A Whitepaper from the Good Governance Institute. GGI Limited, CGI. http:// tinyurl.com/h24obop

Stevens JA (2011) Student nurses' career preferences for working with older people: a replicated longitudinal study. Int J Nurs Stud 48(8): 944-51. https://dx.doi.org/10.1016/j.ijnurstu.2011.01.004 